04

\title{
Кристаллофизическая модель ионного переноса в нелинейно-оптических кристаллах $\mathrm{KTiOPO}_{4}$
}

\author{
(C) Н.И. Сорокин, Ю.В. Шалдин \\ Институт кристаллографии им. А.В. Шубникова ФНИЦ „Кристаллография и фотоника“ РАН, \\ Москва, Россия \\ E-mail: nsorokin1@yandex.ru
}

(Поступила в Редакцию 26 сентября 2017 г.)

\begin{abstract}
Методом импедансной спектроскопии исследована ионная проводимость вдоль главных осей $a, b$ и $c$ элементарной ячейки нелинейно-оптических высокоомных монокристаллов $\mathrm{KTiOPO}_{4}$ (ромбическая сингония, пространственная группа Pna2 1 ), исходных и после термического отжига в вакууме. Кристаллы выращены из раствор-расплава методом Чохральского. Исходные (as grown) кристаллы $\mathrm{KTiOPO}_{4}$ обладают квазиодномерной вдоль кристаллографической оси $c$ электропроводностью, обусловленной миграцией катионов $\mathrm{K}^{+}: \sigma_{\| c}=1.0 \cdot 10^{-5} \mathrm{~S} / \mathrm{cm}$ при $573 \mathrm{~K}$. При этом характеристики анизотропии ионной проводимости кристаллов равны $\sigma_{\| c} / \sigma_{\| a}=3$ и $\sigma_{\| c} / \sigma_{\| b}=24$. Термический отжиг при $1000 \mathrm{~K}$ в течение $10 \mathrm{~h}$ в вакууме увеличивает величину $\sigma_{\| c} \mathrm{KTiOPO}_{4}$ в 28 раз и приводит к росту отношения $\sigma_{\| c} / \sigma_{\| b}=2.1 \cdot 10^{3}$ при $573 \mathrm{~K}$. Предложена кристаллофизическая модель ионного переноса в кристаллах $\mathrm{KTiOPO}_{4}$.
\end{abstract}

DOI: 10.21883/FTT.2018.04.45679.277

\section{1. Введение}

В работах $[1,2]$ у кристаллов титанилфосфата калия $\mathrm{KTiOPO}_{4}$ (ромбическая сингония, пространственная группа Pna2 $2_{1}$ ) обнаружена квазиодномерная вдоль полярной кристаллографической оси $c$ ионная проводимость $\sigma_{\| c}$, которая обусловлена термически активированным движением катионов К. Значения $\sigma_{\| c}$ кристаллов $\mathrm{KTiOPO}_{4}$ могут изменяться в широких пределах $\left(10^{-11}-10^{-4} \mathrm{~S} / \mathrm{cm}\right.$ при $293 \mathrm{~K}$ [3-10]) в зависимости от степени дефектности кристаллической решетки вследствие различных условий их выращивания. Монокристаллы $\mathrm{KTiOPO}_{4}$, получаемые из раствор-расплава методом Чохральского $[11,12]$ и предназначенные для использования в области нелинейной оптики, характеризуются особо низкой концентрацией дефектов и большим электросопротивлением. Нелинейно-оптические высокоомные кристаллы $\mathrm{KTiOPO}_{4}$ применяются в качестве активных элементов для удвоения частоты лазерного излучения, электрооптических модуляторов твердофазных лазеров для параметрической генерации света и волноводов для интегральной оптики [11,13-15].

Целью работы является исследование температурной зависимости ионной проводимости нелинейно-оптических монокристаллов $\mathrm{KTiOPO}_{4}$, исходных и после термического отжига в вакууме, и рассмотрение кристаллофизической модели ионного переноса в этих кристаллах.

\section{2. Методика эксперимента}

Исследуемые монокристаллы $\mathrm{KTiOPO}_{4}$ получены методом направленной раствор-расплавной кристаллизации на затравку в лаборатории выращивания кристаллов Ариельского Университета в Самарии (Израиль) $[11,12]$.
Кристаллы выращены из высокотемпературных растворрасплавов методом Чохральского при медленном охлаждении со скоростью $0.2-0.5 \mathrm{~mm} /$ day (длительность ростовой процедуры 60 дней). Полученные таким способом монокристаллы характеризуются особо низкой концентрацией дефектов и предназначены для использования в области нелинейной оптики. Параметры элементарной ячейки: $a=12.814, b=6.402, c=10.589 \AA[16]$; температуры сегнетоэлектрического перехода и плавления исходных кристаллов $\mathrm{KTiOPO}_{4} \sim 1220$ и $1453 \mathrm{~K}$ соответственно.

Один из исходных (as grown) кристаллов $\mathrm{KTiOPO}_{4}$ был подвергнут термическому отжигу в вакууме при $1000 \mathrm{~K}$ в течение $10 \mathrm{~h}$. После отжига кристалл потерял прозрачность и приобрел черный цвет, что свидетельствует [17] об образовании в нем значительного количества центров окраски, содержащих вакансии кислорода.

Статическую электропроводность $\sigma_{d c}$ (индекс $d c$ означает direct current) кристаллов определяли методом импедансной спектроскопии в диапазонах частот $5-5 \cdot 10^{5} \mathrm{~Hz}$ и сопротивлений $1-10^{7} \mathrm{Ohm}$ (прибор Tesla ВМ-507). Монокристаллические образцы представляли собой плоскопараллельные пластины $Z$-среза толщиной $h=1.6-1.8 \mathrm{~mm}$. Отклонение ориентировки образцов относительно полярного направления (кристаллографической оси $c$ ) не превышало $30^{\prime}$. В качестве электродов использовали серебряную пасту Leitsilber. Площадь контактных поверхностей образцов составляла $S=25 \mathrm{~mm}^{2}$.

Описание экспериментальной кондуктометрической установки (конструкция и изготовление СКБ ИК РАН) дано в работе [18]. Электрофизические измерения кристаллов выполняли в вакууме $\sim 1$ Ра в интервале температур 336-832 K по стабилизированным точкам (время стабилизации точки 10-30 min). Объемное сопротивление кристаллов $R_{b}$ определяли экстраполяцией годографа импеданса на ось активных сопротивлений. Удельную 
электропроводность $\sigma_{d c}$ определяли с учетом геометрических размеров кристалла: $\sigma_{d c}=(h / S) R_{b}^{-1}$. Энтальпию активации ионного транспорта $\Delta H_{\sigma}$ находили из уравнения Аррениуса-Френкеля

$$
\sigma_{d c} T=A \exp \left(-\Delta H_{\sigma} / k T\right),
$$

где $A$ - предэкспоненциальный множитель электропроводности, $k$ - константа Больцмана, $T$ - температура. Кондуктометрические измерения выполнены вдоль главных осей $a, b$ и $c$ элементарной ячейки $\left(\sigma_{\| a}, \sigma_{\| b}\right.$ и $\sigma_{\| c}$, в этих обозначениях индекс $d c$ не будем указывать).

\section{3. Результаты и их обсуждение}

Температурные зависимости ионной проводимости $\sigma_{\| a}(T), \sigma_{\| b}(T)$ и $\sigma_{\| c}(T)$ для исходного кристалла $\mathrm{KTiOPO}_{4}$ показаны на рис. 1. Параметры зависимостей $\sigma_{\| a}(T), \sigma_{\| b}(T)$ и $\sigma_{\| c}(T)$, обработанные в соответствии с уравнением Аррениуса-Френкеля, приведены в таблице. При $573 \mathrm{~K}\left(300^{\circ} \mathrm{C}\right)$ характеристики анизотропного поведения ионного переноса в исходном кристалле составляют: $\sigma_{\| c} / \sigma_{\| b}=24, \sigma_{\| c} / \sigma_{\| a}=3, \sigma_{\| c}=1.0 \cdot 10^{-5} \mathrm{~S} / \mathrm{cm}$. Экстраполяция зависимости $\sigma_{\| c}(T)$ к комнатной температуpe $(293 \mathrm{~K})$ дает величину $3 \cdot 10^{-11} \mathrm{~S} / \mathrm{cm}$ для исходного образца.

Температурные зависимости проводимости $\sigma_{\| b}(T)$ и $\sigma_{\| c}(T)$ для отожженных кристалла $\mathrm{KTiOPO}_{4}$ показаны на рис. 2. К сожалению, температурную зависимость $\sigma_{\| a}(T)$ не удалось измерить. В результате термического отжига в вакууме ионная проводимость кристалла при $573 \mathrm{~K}$ возрастает в 28 раз $\left(\sigma_{\| c}=2.8 \cdot 10^{-4} \mathrm{~S} / \mathrm{cm}\right)$, анизотропия проводимости составляет $\sigma_{\| c} / \sigma_{\| b} \approx 2.1 \cdot 10^{3}$. Экстраполяция зависимости $\sigma_{\| c}(T)$ к комнатной температуре $(293 \mathrm{~K})$ дает величину $3 \cdot 10^{-10} \mathrm{~S} / \mathrm{cm}$ для отожженного образца.

Сильная анизотропия ионной проводимости кристаллов $\mathrm{KTiOPO}_{4}$ обусловлена их канальной структурой. Ионный перенос происходит в калиевой подрешетке по вакансионному механизму, при этом носителями заряда являются подвижные вакансии калия $V_{\mathrm{K}}^{-}$. Вакансии $V_{\mathrm{K}}^{-}$

Температурные интервалы $(\Delta T)$ и параметры уравнения Френкеля-Аррениуса $\left(A, \Delta H_{\sigma}\right)$ для ионной проводимости монокристаллов $\mathrm{KTiOPO}_{4}$

\begin{tabular}{c|c|c|c|c}
\hline \multirow{2}{*}{ Кристаллы } & $\begin{array}{c}\text { Ориентация } \\
\text { кристалла }\end{array}$ & $\begin{array}{c}\Delta T, \\
\mathrm{~K}\end{array}$ & $\begin{array}{c}A, \\
\mathrm{~S} \cdot \mathrm{K} / \mathrm{cm}\end{array}$ & $\begin{array}{c}\Delta H_{\sigma}, \\
\mathrm{eV}\end{array}$ \\
\hline \multirow{2}{*}{ Исходный } & $\|$ оси $c$ & $564-832$ & $6.7 \cdot 10^{3}$ & 0.69 \\
\cline { 2 - 5 } & $\|$ оси $b$ & $578-684$ & $8.8 \cdot 10^{3}$ & 0.86 \\
\cline { 2 - 5 } & \multirow{2}{*}{ оси $a$} & $565-710$ & $1.25 \cdot 10^{5}$ & 0.89 \\
& & $734-829$ & $3.4 \cdot 10^{3}$ & 0.66 \\
\hline \multirow{2}{*}{ Отожженный } & \multirow{2}{*}{ оси $c$} & $336-574$ & $5.1 \cdot 10^{5}$ & 0.74 \\
& $\|$ оси $b$ & $596-785$ & $3.0 \cdot 10^{4}$ & 0.98
\end{tabular}

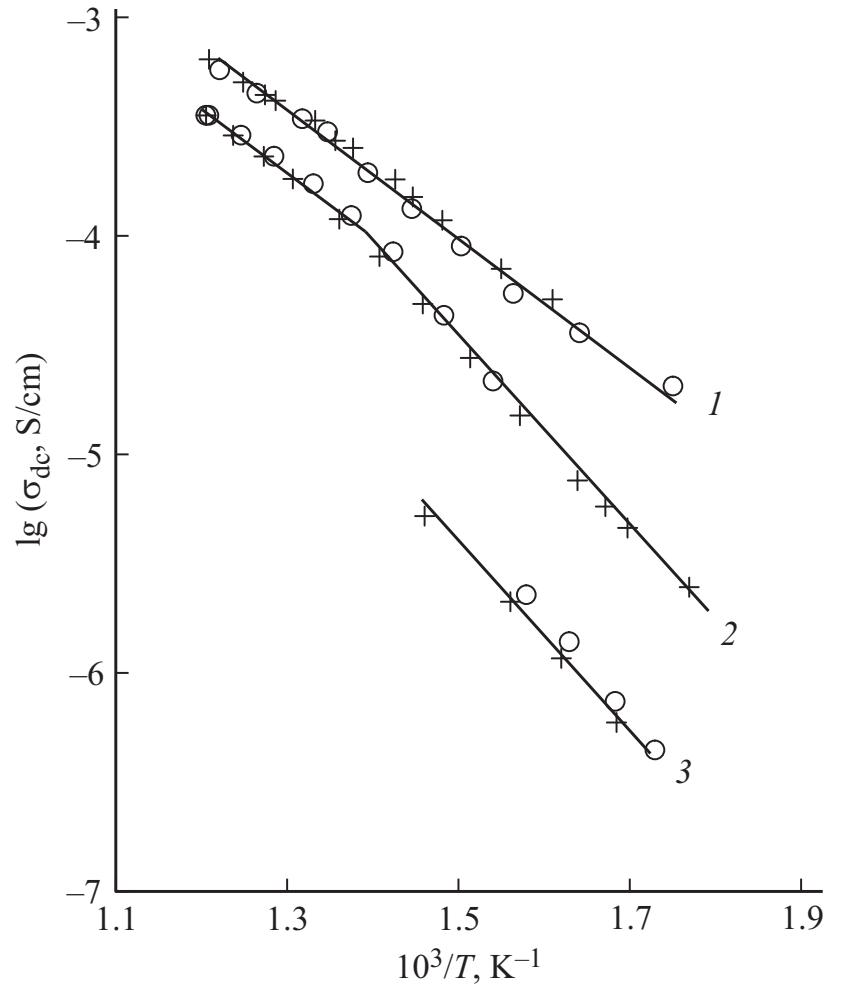

Рис. 1. Температурные зависимости ионной проводимости $\sigma_{d c}(T)$ исходного монокристалла $\mathrm{KTiOPO}_{4}: 1-\sigma_{\| c}(T)$, $2-\sigma_{\| b}(T), 3-\sigma_{\| a}(T)$. Кружки - нагрев, крестики охлаждение.

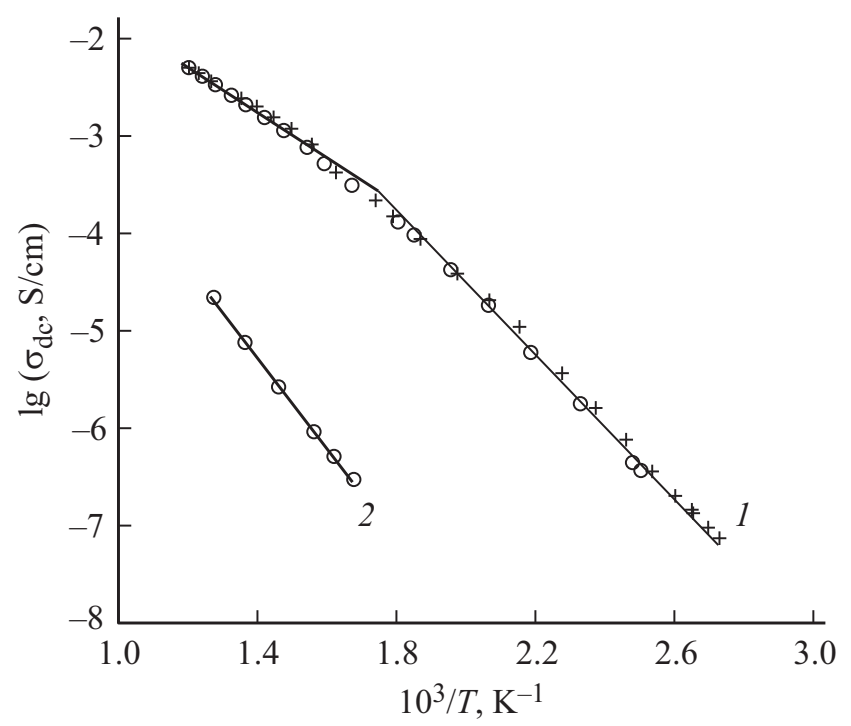

Рис. 2. Температурные зависимости ионной проводимости $\sigma_{d c}(T)$ монокристалла $\mathrm{KTiOPO}_{4}$, отожженного в вакууме: $1-\sigma_{\| c}(T), 2-\sigma_{\| b}(T)$. Кружки - нагрев, крестики охлаждение.

образуются при росте кристаллов $[19,20]$ :

$$
\mathrm{KTiOPO}_{4} \rightarrow \mathrm{K}_{1-x} \mathrm{TiOPO}_{4-x / 2}+(x / 2) \mathrm{K}_{2} \mathrm{O},
$$

где $x$ - мольная доля вакансий $V_{\mathrm{K}}^{-}$в калиевой подрешетке, $x / 2$ - мольная доля вакансий $V_{O}^{++}$в подрешетке 
кислорода. Структурные дефекты сильно влияют на физические свойства и эксплуатационные характеристики выращенных монокристаллов $\mathrm{KTiOPO}_{4}$.

Черный цвет отожженного кристалла свидетельствует о появлении в его структуре значительного количества вакансий кислорода:

$$
2 \mathrm{O}_{\mathrm{O}}^{x} \rightarrow 2 V_{\mathrm{O}}^{++}+\mathrm{O}_{2 \text { (газ) }}+4 e^{-} .
$$

Согласно уравнению (2), образование вакансий кислорода в кристалле приводит к появлению в два раза большего количества вакансий калия:

$$
\mathrm{K}_{1-x} \mathrm{TiOPO}_{4-x / 2} \rightarrow x V_{\mathrm{K}}^{-}+x / 2 V_{\mathrm{O}}^{++} .
$$

В диапазоне измеряемых температур подвижность однозарядных вакансий $V_{\mathrm{K}}^{-}$в структурных каналах значительно выше, чем двухзарядных вакансий $V_{\mathrm{O}}^{++}$в кристаллическом каркасе. К тому же ионы кислорода связаны сильными ковалентными связями в $\left[\mathrm{TiO}_{6}\right]$-октаэдрах и $\left[\mathrm{PO}_{4}\right]$-тетраэдрах. Поэтому усиление дефектности по кислороду в отожженном кристалле $\mathrm{KTiOPO}_{4}$ сопровождается ростом $\mathrm{K}^{+}$-ионной проводимости в направлении оси $c$ и незначительным изменением ионной проводимости в направлении, перпендикулярном оси $c$ (рис. 1, 2). Положительное влияние термического отжига кристалла $\mathrm{KTiOPO}_{4}$ в вакууме на его ионную проводимость обусловлено появлением дополнительного количества подвижных вакансий $V_{\mathrm{K}}^{-}$.

Структурные исследования кристаллов $\mathrm{KTiOPO}_{4}$ выполнены в работах $[16,21,22]$. Кристаллы $\mathrm{KTiOPO}_{4}$ относятся к ромбической сингонии, нецентросимметричная пространственная группа Pna2 $2_{1}$ Трехмерный кристаллический каркас титанилфосфата калия образуют соединенные вершинами титан-кислородные октаэдры $\left[\mathrm{TiO}_{6}\right]$ и фосфор-кислородные тетраэдры $\left[\mathrm{PO}_{4}\right]$. В структуре имеются широкие винтообразные каналы, вытянутые вдоль кристаллографической оси $c$, в которых размещаются одновалентные щелочные катионы. Ионы $\mathrm{K}^{+}$, расположенные в структурных каналах, слабо связаны с ионами кислорода из кристаллического каркаса. Существование каналов в структуре $\mathrm{KTiOPO}_{4}$ приводит к квазиодномерной прыжковой миграции ионов $\mathrm{K}^{+}$вдоль кристаллографической оси $c$.

Под данным работы [21], в структуре $\mathrm{KTiOPO}_{4}$ имеются две независимые кристаллографические позиции для атомов калия, которые различаются координацией по кислороду: КЧ $=8$ для атомов $\mathrm{K} 1$, КЧ $=9$ для атомов К2. В более поздних структурных исследованиях $[16,22]$ кристаллов $\mathrm{KTiOPO}_{4}$ обнаружено расщепление калиевых позиций К 1 и К2: $\mathrm{K} 1-\mathrm{K}^{\prime}=0.347 \AA$, $\mathrm{K} 2-\mathrm{K} 2^{\prime}=0.279 \AA$. С ростом температуры происходит дальнейшее расщепление калиевых позиций, и изменяется их заселенность [23].

Пути проводимости в кристаллах семейства титанилфосфата калия изучены в работах [23-25]. На рис. 3 показан один из путей движения ионов $\mathrm{K}^{+}$вдоль оси $c$ (кристаллографическое направление [001]). $\mathrm{K}^{+}$-ионная

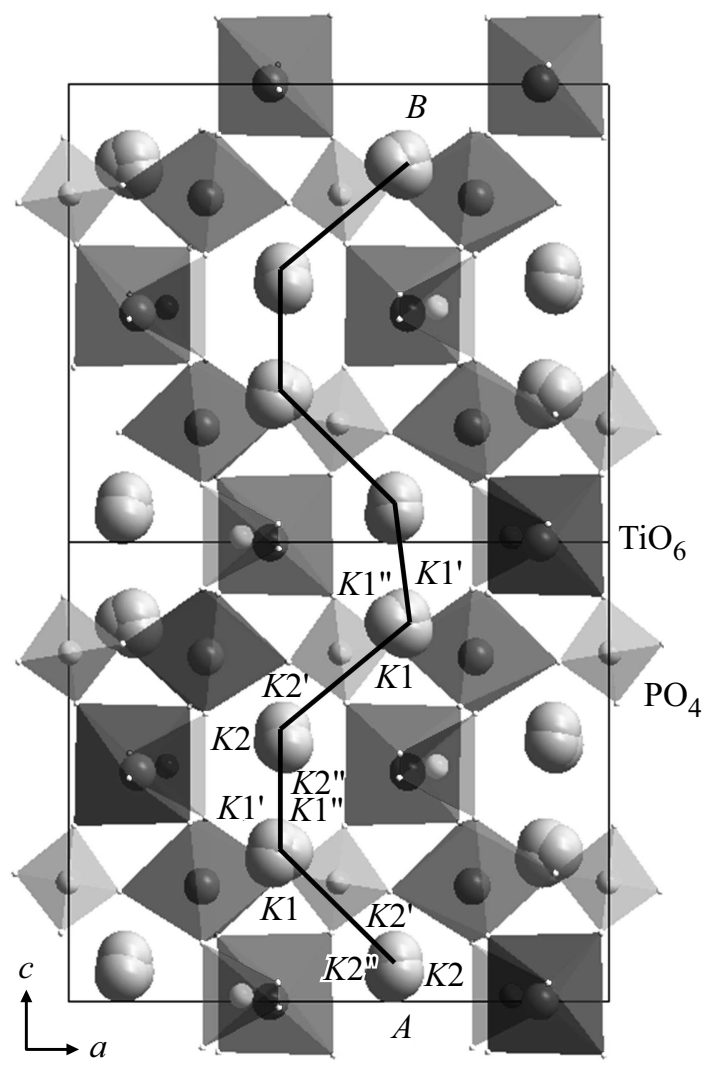

Рис. 3. Структура $\mathrm{KTiOPO}_{4}, A B-$ путь проводимости вдоль кристаллографической оси $c$ (направление [001]) [25].

проводимость кристаллов $\mathrm{KTiOPO}_{4}$ обусловлена наличием в их структуре винтообразных каналов, вытянутых вдоль полярной оси $c$, образованием вакансий $V_{\mathrm{K}}^{-}$во время роста кристаллов при высоких температурах и расщеплением калиевых позиций, приводящим к статистическому разупорядочению ионов $\mathrm{K}^{+}$в кристаллической решетке. Механизм ионной проводимости является эстафетным (кооперативным) и осуществляется прыжками катионов $\mathrm{K}^{+}$по вакантным кристаллографическим позициям.

\section{4. Заключение}

Метод ионной проводимости позволяет контролировать степень дефектности кристаллической решетки $\mathrm{KTiOPO}_{4}$ и выявить (в сочетании со структурными исследованиями) причины изменения их ионопроводящих свойств. Для монокристаллов $\mathrm{KTiOPO}_{4}$ подтверждена анизотропия ионной проводимости, которая составляет $\sigma_{\| c} / \sigma_{\| b}=24$ и $\sigma_{\| c} / \sigma_{\| a}=3$ при $573 \mathrm{~K}$. Вакуумный термический отжиг кристаллов $\mathrm{KTiOPO}_{4}$ при $1000 \mathrm{~K}$ в течение $10 \mathrm{~h}$ увеличивает величину $\sigma_{\| c}$ в 28 раз, при этом анизотропия электропроводности возрастает: $\sigma_{\| c} / \sigma_{\| b}=2.1 \cdot 10^{3}$ (при $573 \mathrm{~K}$ ).

Основным структурным фактором, влияющим на величину ионной проводимости монокристаллов 
$\mathrm{KTiOPO}_{4}$, является разупорядочение подрешетки щелочных катионов, связанное с образованием в ней подвижных вакансий калия и расщеплением калиевых позиций. Для применения монокристаллов семейства титанилфосфата калия в области нелинейной физики необходимо отбирать высокоомные образцы с малой концентрацией дефектов.

Авторы благодарят М. Цейтлина (Ариельский университет в Самарии, Израиль) за предоставленные монокристаллы для исследований и Н.Е. Новикову за выполнение рис. 3.

\section{Список литературы}

[1] В.А. Калесинкас, Н.И. Павлова, И.С. Рез, Й.П. Григас. Лит. физ. сборник. 22, 87 (1982).

[2] В.К. Яновский, В.И. Воронкова. ФТТ 27, 2183 (1985).

[3] J. D. Bierlein, C.B. Arweiler. Appl. Phys. Lett. 49, 917 (1986).

[4] И.М. Сильвестрова, В.А. Маслов, Ю.В. Писаревский. Кристаллография 37, 1227 (1992).

[5] S. Sigaryov. J. Phys. D 26, 1326 (1993).

[6] A. Pimenov, C.H. Ruscher, V.A. Maslov. Solid State Commun. 97, 913 (1996).

[7] K. Noda, W. Sakamoto, T. Yogo, S. Hirano. J. Mater. Sci. Lett. 19, 69 (2000).

[8] P. Urenski, N. Gorbatov, G. Rosenman. J. Appl. Phys. 89, 1850 (2001).

[9] J.H. Park, C.S. Kim, B.C. Choi, B.K. Moon, H.J. Seo. Appl. Phys. A 78, 745 (2004).

[10] В.Г. Гуртовой, А.У. Шелег, С.А. Гурецкий, Н.А. Каланда. Кристаллография 53, 720 (2008).

[11] www.raicol.com

[12] N. Angert, L. Kaplun, M. Tseitlin, M. Yashchin, M. Roth. J. Cryst. Growth. 137, 116 (1994).

[13] F.G. Zumsteg. Lazer Focus 14, 18 (1978).

[14] А.Л. Александровский, С.А. Ахманов, В.А. Дьяков, Н.И. Желудев, В.И. Прялкин. Квантовая электроника 12, 1333 (1985).

[15] В.А. Русов, В.А. Серебряков, А.Б. Каплун, А.В. Горчаков. Оптический журнал 76, 6 (2009).

[16] Н.Е. Новикова, И.А. Верин, Н.И. Сорокина, О.А. Алексеева, В.И. Воронкова, М. Цейтлин, М. Рот. Кристаллография 53, 999 (2008).

[17] Ю.В. Шалдин, С. Матыясик, М. Цейтлин, М. Рот. ФТТ 50, 1263 (2008).

[18] А.К. Иванов-Шиц, Н.И. Сорокин, П.П. Федоров, Б.П. Соболев. ФТТ 25, 1748 (1983).

[19] N. Angert, M. Tseitlin, E. Yashin, M. Roth. Appl. Phys. Lett. 67, 1941 (1995).

[20] Н.И. Сорокина, В.И. Воронкова. Кристаллография 52, 82 (2007).

[21] I. Tordjman, R. Masse, C. Guitel. Z. Kristal. 139, 103 (1974).

[22] S. Norberg, N. Ishizawa. Acta Cryst. C 61, 99 (2005).

[23] M. Yashima, T. Komatsu. Chem. Commun. 1070 (2009)

[24] Е.Л. Белоконева, Б.В. Милль. ЖНХ 39, 355 (1994).

[25] Н.И. Сорокин, Н.Е. Новикова, Ю.В. Шалдин, М. Цейтлин. Кристаллография, в печати. 